\title{
Determinants of inadequate minimum dietary diversity among children aged 6-23 months in Ethiopia: secondary data analysis from Ethiopian Demographic and Health Survey 2016
}

Tewodros Eshete ${ }^{1 *}$, Gemechu Kumera ${ }^{1}$, Yibelu Bazezew ${ }^{2}$, Abebe Mihretie $^{3}$ and Tefera Marie $^{2}$

\begin{abstract}
Background: Inadequate feeding practices are a significant reason for the onset of malnutrition in young children, and their consequences are one of the major obstacles to sustainable socioeconomic development and poverty reduction. Dietary diversity is one of the useful indicators to assess the nutrient adequacy and can examine how different food groups contribute to the nutrient adequacy of the diet in a specific area. Minimum dietary diversity is the intake of at least four food types from the seven categories.

Methods: Secondary data analysis of Ethiopian Demographic health survey of 2016 was conducted to explore significant predictors that make children inappropriate to meet minimum dietary diversity. There were 2972 weighted samples, and we have used "SVY" command by STATA 14.0 during data analysis to run the complex survey data. This study has identified the possible factors of inadequate minimum dietary diversity of children.

Results: The proportion of inadequate minimum dietary diversity in Ethiopia was found $85.1 \%$. Frequency of reading newspaper or magazine, frequency of listening to radio, father's educational level and household wealth index were found significant predictors to determine the minimum dietary diversity of children. Dairy products and grain, roots and tubers account more than half of consumed foods. Among breastfed children who attained minimum dietary diversity, majority of them were in the age group of 6-11 months.

Conclusions: Minimum dietary diversity is still low in Ethiopia, and most of mothers feed their child the most and easy accessible food rather than of diverse food. In the way of addressing the Sustainable Development Goal, Ethiopia requires substantial improvement in complementary feeding practices. Appropriate infant and young child feeding messages should to be developed and delivered through mass media.
\end{abstract}

Keywords: Minimum dietary diversity, EDHS, Inappropriate complementary feeding, Food groups

\section{Background}

Globally, inadequate feeding practices and their outcomes are still one of the real impediments to sustainable socioeconomic development and poverty reduction.

\footnotetext{
*Correspondence: teddyeshet143@gmail.com

1 Department of Public Health, College of Medicine and Health Sciences

(CMHS), Debre Markos University (DMU), Debre Markos, Ethiopia

Full list of author information is available at the end of the article
}

Countries will not be productive in their endeavors to quicken economic development in any significant long haul sense until optimal child growth and development, particularly thorough appropriate feeding practices, are ensured [1]. In addition, inappropriate feeding practices are a significant reason for the onset of malnutrition in young children [2].

Adequate nutrition allows children to grow, develop, learn, play, participate and contribute, while under 
nutrition robs children of their futures and leaves young lives hanging in the balance. Stunting is one of the main reasons that may make children never grow to their full height, and their brains may never develop to their full cognitive potential [3]. Universally, 151 million children younger than 5 years old were stunted (too short for their age) during 2017, with $75 \%$ of such children living in the WHO African Region or World Health Organization (WHO) South East Asia Region. During the year of 2017, 51 million children under the age of five were wasted (too light for their height) which is also a major cause of burden preventing children who survive from reaching their full development potential [4].

Except if massive improvements in child nutrition are made, it will be hard to accomplish the ambitious Sustainable Development Goals (SDGs) which target by 2030 to end all types of malnutrition, including achieving, by 2025 , the universally agreed targets on reduction of stunting and wasting in children younger than 5 years of age, and address the nutritious needs of adolescent girls, pregnant and lactating women and older persons [4].

Because of the rapid rate of growth and development during the first 2 years ("critical window"), nutrient needs per body weight of infants and young children are high which makes breast milk insufficient to provide all the needs [2]. Complementary feeding is defined as the process starting other foods and liquids, along with breast milk, when breast milk is no longer sufficient to meet the nutritional requirements of infants. Even though breastfeeding may continue beyond 2 years, the target range for complementary feeding is generally taken to be 6-23 months of age [5].

World Health Organization published document in 2008 presented fifteen indicators to assess infant and young child feeding practice that includes eight cores (early initiation of breastfeeding, exclusive breastfeeding under 6 months, continued breastfeeding at first year, introduction of solid, semisolid or soft foods, minimum dietary diversity, minimum meal frequency, minimum acceptable diet and consumption of iron-rich or ironfortified foods) and seven optional indicators (children ever breastfed, continued breastfeeding at second years, age-appropriate breastfeeding, predominant breastfeeding under 6 months, duration of breastfeeding, bottlefeeding and milk feeding frequency for non-breastfed children). Indicators for dietary diversity (a proxy for adequate micronutrient-density of foods and liquids other than breast milk), feeding frequency (a proxy for adequate energy intake from non-breast milk sources) and minimum acceptable diet among breastfed and non-breastfed children aged between 6 and 23 months were categorized as the cores list. From these indicators, minimum dietary diversity assesses food intake among children age 6-23 months from at least four food groups. Using four food groups as the cutoff is linked with betterquality diets for both non-breastfed and breastfed children [5].

Dietary diversity is one of the useful indicators to assess the nutrient adequacy. It is also able to examine how different food groups contribute to the nutrient adequacy of the diet in a specific area [6]. Besides, dietary diversity is a significant predictor of stunting which enables interventions aimed at improving it can play a pivotal role in reducing the long-term burden of stunting among infants and young children [7]. Generally, the nutritional status of children can significantly be determined by the dietary diversity [8].

Most of developing countries are poorly practicing complementary feeding and are even worsening in some of them [9]. In 2005, Productive Safety Net Program (PSNP) was established by the government of Ethiopia, world food program and development partners collaboratively to increase families' long-term resilience to food shortages. The birth of PSNP is gone for empowering the rural poor confronting chronic food insecurity to oppose shocks, make resources and move toward becoming sustenance independent. The impact of PSNP was assessed in 2008 and showed some positive effect on a livelihood and food security [10].

All things considered, Ethiopia has been attacked by El Nino related drought since 2015 which greatly increased food insecurity level and malnutrition rate particularly worsen in some regions. One of the worst droughts in decades (El Nino) brings failure of the main rainy season which is vital for producing more than $80 \%$ of Ethiopia's agricultural yield-in a main sector that more than $80 \%$ of the country's populations rely on [11, 12]. The current study aimed to explore the predictors of poor complementary feeding by using MDD and provide some critical insights for policy makers as well as helps further research to explore the current situation, trends and reasons for failure of interventions.

\section{Methods \\ Source of data}

The present study examined the 2016 Ethiopia Demographic and Health Survey (2016 EDHS), which is the fourth in a series of Demographic and Health Surveys conducted in Ethiopia in 2000, 2005 and 2011. The 2016 EDHS sample is stratified and was selected in two stages. Administratively, Ethiopia is divided into 11 geographic regions. Each region was stratified into urban and rural areas, which yielded 21 sampling strata. In the first stage, 645 enumeration areas (EAs) were selected with probability proportional to the EA size 
and with independent selection in each sampling stratum. An EA is a geographic area that covers an average of 181 residential households as determined in the 2007 Population and Housing Census. In the second stage of selection, a fixed number of 28 households for every cluster were selected with an equal probability systematic selection from the newly created household listing.

The survey had a total of 18,008 households selected for the sample, of which 17,067 were available. Of the available households, 16,650 were successfully interviewed which provides a response rate of $98 \%$. In the interviewed households, there were 16,583 eligible women for individual interviews. Successful interviews were conducted among 15,683 women, yielding a response rate of $95 \%$. Women who had no less than one child living with them who was born in 2014 or later were asked questions about the types of liquids and foods the child had consumed during the day or night before the interview. Mothers who had more than one child born in 2014 or a later year were asked questions about the youngest child living with them [14]. Our analysis was done among last born living children aged 6-23 months, living with the respondent (ever married women of 15-49 years and usual residents), total weighted sample size was 2972 .

\section{Variables}

\section{Outcome variable}

The MDD is defined as the proportion of children aged 6-23 months who consumed foods from at least four food groups out of the seven referenced food groups within a $24-\mathrm{h}$ time. The seven food groups are: 1 -grains, roots and tubers, 2-legumes and nuts, 3-dairy products, 4-flesh foods (meat, fish, poultry and liver/organ meats), 5-eggs, 6-vitamin A-rich fruits and vegetables and 7-other fruits and vegetables [4]. In the present study, those children between 6 and 23 months who have taken at least four food groups in the last $24 \mathrm{~h}$ before interview are considered as they achieved the MDD adequately. Therefore, the outcome variable is categorized as (" 0 "- adequate minimum dietary diversity, " 1 "-inadequate minimum dietary diversity).

\section{Explanatory variables}

The explanatory variables were found from different literature and grouped as characteristics of the child, parental, family/household, healthcare services and the community. The child characteristics included sex, age [5], birth order and having common childhood illnesses, and the paternal characteristics included for each parent's educational level, literacy level, working status and mother's age, and maternal marital status. The household source of drinking water [13], wealth index and exposure to media were considered as key household characteristics, whereas the nature of residence (urban or rural) was considered as community-level variable. As health service characteristics antenatal visits, place of delivery and timing of post-natal care were included. The information about variables had been described in detail in the EDHS report [14].

\section{Statistical analysis}

Complementary feeding indicator (outcome variable) was dichotomized with category 1 for not meeting the indicator criteria and category 0 for meeting the indicator criteria. After the data cleaning is conducted intensively, the outcome variable was examined against different set of independent variables (individual, parental, household, healthcare and community-level characteristics) to identify factors associated with not meeting the indicator criteria. Data analysis was performed by considering sampling weight, and the survey "SVY" commands of Stata version 14.0 were used for adjustments of DHS' complex sampling design when estimating confidence intervals. The analysis of factors is conducted using sampling weights which denote the inverse of the probability that the observation is included because of the sampling design. Bivariate logistic regression was used to examine the impact of each independent variable on the outcome. Variables that satisfied the cutoff point of $p$ value $\leq 0.25$ became candidate for the multiple logistic regression model. But those variables with statistical significance of $p<0.05$ remained in the final model. To look to the final model fitness, Hosmer and Lemeshow goodness-of-fit test was used [15]. Multicollinearity among independent variables was also assessed using variance inflation factor (VIF).

\section{Results}

In our study, the minimum dietary diversity was $14.9 \%$ which is slightly higher than the EDHS report of $13.8 \%$. Since Ethiopia is one of the developing countries where most of mothers living in rural areas, majority $(88.35 \%)$ of our respondents were living in there. Majority of the children born were female 1575 (53.03\%) and aged between 12 and 17 months (36.73\%). Most of mothers (52.25\%) aged between 25 and 34 years old and those who have not get into any formal education took the majority (62.02\%). Most of mothers $(57.43 \%)$ have not directly engaged in income generating occupations. But, agricultural works remained highly prevalent work among mothers $(21.60 \%)$ and fathers (61.47\%) of children aged 6-23 months. The current study has revealed that mother's exposure to mass media was low. From the interviewed mothers $1.77 \%$ reads newspaper, $13.73 \%$ listen to radio and $9.03 \%$ 
watches television at least once in a week. Most (57.05\%) of Ethiopian mothers of children aged 6-23 months provide complementary feeding using improved water sources, and also majority of mothers were living below the middle level of household wealth index. Majority of the respondents $(66.3 \%)$ waits more than 2 years to give birth to their living youngest child. Ethiopia still has a work to do in institutional delivery because around $62 \%$ of delivery was conducted in home. Almost one-third of mothers gave birth to child without having any antenatal care visit in the health institution. Besides, postnatal check-up within 2 months after delivery was not conducted for majority $(88.43 \%)$ of mothers. Table 1 has shown different individual, parental, household, healthcare and community-level characteristics of last children who are living with their mother and aged between 6 and 23 months.

Minimum dietary diversity rate among children aged 6-23 months was also described with their current breastfeeding status. There was high rate of MDD among breastfeeding children in the all age classification [(6-11 months), (12-17 months), (18-23 months)]. Among breastfed children who attained MDD, majority of them were in the age group of 6-11 months next in 18-23 months which accounts $9.6 \%$ and $7.25 \%$, respectively. The least (5.8\%) were in 12-17 months age group. From those children who attained the MDD and not breastfeeding, majority rate $(5.5 \%)$ was from the age group of 18-23 months. The least MDD rate was scored among children aged 6-11 months who were not breastfeeding during the interview (Table 2).

By controlling for possible confounders, variables which remained in the final model were frequency of reading to newspaper or magazine, frequency of listening to radio, father's educational level and household wealth index. Those children whose mothers read to newspaper or magazine at least once in a week had $81 \%$ less chance to be inadequate for MDD. Furthermore, statistically significant result has shown that the odds of being inadequate to minimum dietary diversity among children whose mothers read to newspaper or magazine less than once in a week was $56 \%$ less likely (AOR $=0.44 ; 95 \% \mathrm{CI}$ $0.23,0.83$ ) than those children's mother who do not read at all. Likewise, the odds of being inadequate to MDD among children who had mothers that listen to radio at least once in a week was $57 \%$ less likely than $(A O R=0.43$; $95 \%$ CI $0.30,0.62$ ) those children who had mothers that did not listen at all. Those fathers who had attained primary education had $41 \%$ less likely $(\mathrm{AOR}=0.59 ; 95 \% \mathrm{CI}$ $0.37,0.94$ ) odds of having children who are inadequate to minimum dietary diversity than fathers who did not go to formal education. The odds of having inadequate minimum dietary diversity among children living in richest
Table 1 Individual, parental, household, healthcare and community-level characteristics of living children aged between 6 and 23 months, Ethiopia, 2016

\begin{tabular}{|c|c|c|}
\hline Characteristics & $n$ & $\%$ \\
\hline \multicolumn{3}{|l|}{ Child characteristics } \\
\hline \multicolumn{3}{|l|}{ Sex of child } \\
\hline Male & 1396 & 46.97 \\
\hline Female & 1576 & 53.03 \\
\hline \multicolumn{3}{|l|}{ Age of child (months) } \\
\hline $6-11$ & 1044 & 35.14 \\
\hline $12-17$ & 1091 & 36.73 \\
\hline $19-23$ & 836 & 28.13 \\
\hline \multicolumn{3}{|l|}{ Birth order } \\
\hline Firstborn & 547 & 18.4 \\
\hline Second to fourth & 1284 & 43.2 \\
\hline Five or more & 1141 & 38.4 \\
\hline \multicolumn{3}{|l|}{ Diarrhea $^{a}$} \\
\hline No & 2394 & 80.54 \\
\hline Yes & 573 & 19.28 \\
\hline \multicolumn{3}{|l|}{ Cough } \\
\hline No & 2267 & 76.29 \\
\hline Yes & 705 & 23.71 \\
\hline \multicolumn{3}{|l|}{ Parental characteristics } \\
\hline \multicolumn{3}{|l|}{ Mother's age (years) } \\
\hline $15-24$ & 805 & 27.08 \\
\hline $25-34$ & 1553 & 52.25 \\
\hline $35-49$ & 614 & 20.67 \\
\hline \multicolumn{3}{|l|}{ Mother's education } \\
\hline No education & 1844 & 62.02 \\
\hline Primary education & 904 & 30.40 \\
\hline Secondary and higher & 225 & 7.58 \\
\hline \multicolumn{3}{|l|}{ Mother's occupation } \\
\hline Not working & 1707 & 57.43 \\
\hline Non agricultural works & 590 & 19.84 \\
\hline Agricultural works & 642 & 21.60 \\
\hline Others & 33 & 1.13 \\
\hline \multicolumn{3}{|l|}{ Mother's literacy } \\
\hline Cannot read at all & 2203 & 74.11 \\
\hline Able to read only parts of sentence & 356 & 11.98 \\
\hline Able to read whole sentence & 413 & 13.91 \\
\hline \multicolumn{3}{|l|}{ Mother's marital status } \\
\hline Currently married & 2838 & 95.49 \\
\hline Formerly married & 134 & 4.51 \\
\hline \multicolumn{3}{|l|}{ Reads newspaper or magazine } \\
\hline Not at all & 2777 & 93.45 \\
\hline Less than once a week & 142 & 4.78 \\
\hline At least once a week & 53 & 1.77 \\
\hline \multicolumn{3}{|l|}{ Listen to radio } \\
\hline Not at all & 2177 & 73.25 \\
\hline Less than once a week & 387 & 13.02 \\
\hline At least once a week & 408 & 13.73 \\
\hline
\end{tabular}


Table 1 (continued)

\begin{tabular}{|c|c|c|}
\hline Characteristics & $n$ & $\%$ \\
\hline \multicolumn{3}{|l|}{ Watches television } \\
\hline Not at all & 2446 & 82.27 \\
\hline Less than once a week & 258 & 8.70 \\
\hline At least once a week & 268 & 9.03 \\
\hline \multicolumn{3}{|l|}{ Father's education } \\
\hline No education & 1254 & 42.18 \\
\hline Primary & 1177 & 39.62 \\
\hline Secondary and higher & 385 & 12.96 \\
\hline Don't know and missing & 136 & 5.26 \\
\hline \multicolumn{3}{|l|}{ Father's occupation } \\
\hline Not working & 219 & 7.38 \\
\hline Non agricultural works & 678 & 22.82 \\
\hline Agricultural works & 1827 & 61.47 \\
\hline Others and missing & 248 & 8.33 \\
\hline \multicolumn{3}{|l|}{ House hold characteristics } \\
\hline \multicolumn{3}{|l|}{ Source of drinking water } \\
\hline Improved & 1696 & 57.05 \\
\hline Un improved & 1276 & 42.95 \\
\hline \multicolumn{3}{|l|}{ Household wealth index } \\
\hline \multicolumn{3}{|l|}{ Poorest } \\
\hline Poorer & 627 & 21.09 \\
\hline Middle & 666 & 22.41 \\
\hline Richer & 544 & 18.31 \\
\hline Richest & 434 & 14.61 \\
\hline \multicolumn{3}{|l|}{ Healthcare characteristics } \\
\hline \multicolumn{3}{|l|}{ Preceding birth interval } \\
\hline No preceding birth & 549 & 18.5 \\
\hline$<24$ months & 451 & 15.2 \\
\hline$\geq 24$ months & 1972 & 66.3 \\
\hline \multicolumn{3}{|l|}{ Antenatal care visit } \\
\hline None & 1002 & 33.71 \\
\hline $1-3$ times & 870 & 29.28 \\
\hline 4 and above & 987 & 33.21 \\
\hline I don't know and missing & 113 & 3.80 \\
\hline \multicolumn{3}{|l|}{ Mode of delivery } \\
\hline Non-Cesarean section & 2897 & 97.48 \\
\hline Cesarean section & 75 & 2.52 \\
\hline \multicolumn{3}{|l|}{ Place of delivery } \\
\hline Home & 1845 & 62.05 \\
\hline Health facility & 1068 & 35.95 \\
\hline Other & 59 & 2.00 \\
\hline \multicolumn{3}{|c|}{ Post-natal check-up within 2 months } \\
\hline No & 2628 & 88.43 \\
\hline Yes & 232 & 7.79 \\
\hline I don't know and missing & 112 & 3.78 \\
\hline \multicolumn{3}{|l|}{ Community-level factors } \\
\hline \multicolumn{3}{|l|}{ Residence } \\
\hline Urban & 346 & 11.65 \\
\hline Rural & 2626 & 88.35 \\
\hline
\end{tabular}

Table 1 (continued)

\begin{tabular}{lll}
\hline Characteristics & $\boldsymbol{n}$ & $\%$ \\
\hline Minimum dietary diversity & & \\
Adequate minimum dietary diversity & 443 & 85.1 \\
Inadequate minimum dietary diversity & 2529 & \\
Total & 2972 & \\
\hline a For having diarrhea recently 5 respondents responded "I don't know"
\end{tabular}

household was $60 \%$ ( $\mathrm{AOR}=0.40 ; 95 \% \mathrm{CI} 0.21,0.76)$ less likely than children who were living in poorest household (Table 3).

Based on our criteria of beta coefficient change greater than twenty percent, there was no significant confounder or interaction observed. The significance level of Hosmer-Lemeshow test for goodness of fit was 0.33. Since the probability is greater than 0.05 , we fail to reject the null hypothesis and shows that there is no significant difference between the observed and model-predicted values. Therefore, our final model fit the data well. The final model of this study showed that the mean value of VIF was 1.45 which indicated there was no multicollinearity in the final model (Fig. 1).

\section{Discussion}

The present study has analyzed the nationally representative data from the 2016 Ethiopia Demographic health survey and reveals the important gaps in meeting the minimum dietary diversity criteria by WHO for children aged 6-23 months. We have found prevalence of minimum dietary diversity rate as $14.9 \%$ which is slightly higher than the national EDHS report of 2016 [14]. This can be due to the reason that for analyzing to the factors and to give equal chance for all respondents we have cleaned the data set based on important variables (Table 4).

One of the factors that the current study has identified is the impact of mother's access to mass media. Those mothers who read newspaper or magazine at least once in a week have low chance to be inadequate in meeting minimum dietary diversity of their young infant. This finding is concurrent with the study conducted in Nepal and India $[16,17]$. Besides, mothers who listen to a radio within a week are also able to feed different food groups to their child and meet the minimum dietary diversity intake. Listening to radio is found a significantly affecting factor in an Indian study conducted using secondary analysis of the national family health survey [17]. Another study conducted in North West Ethiopia and Bangladesh also came up with the same finding that shows mother's exposure to mass media remains positively associated 
Table 2 Types of foods given to children aged 6-23 months a day before the interview, EDHS, 2016

\begin{tabular}{|c|c|c|c|c|c|c|c|}
\hline \multirow[t]{3}{*}{ Food groups } & \multicolumn{6}{|c|}{ Age of a child (months) } & \multirow[t]{3}{*}{$N$} \\
\hline & \multicolumn{2}{|l|}{$6-11$} & \multicolumn{2}{|c|}{$12-17$} & \multicolumn{2}{|c|}{$18-23$} & \\
\hline & $n$ & $\%$ & $n$ & $\%$ & $n$ & $\%$ & \\
\hline Grain, roots and tubers & 519 & 28 & 734 & 39.7 & 596 & 32.3 & 1849 \\
\hline Legumes and nuts & 186 & 30 & 233 & 38 & 194 & 32 & 613 \\
\hline Dairy products & 403 & 35.4 & 411 & 36.1 & 324 & 28.5 & 1138 \\
\hline Flesh foods & 46 & 18.4 & 122 & 48.8 & 82 & 32.8 & 250 \\
\hline Eggs & 154 & 31.3 & 189 & 38.4 & 149 & 30.3 & 492 \\
\hline Vitamin A-rich fruits and vegetables & 206 & 25.1 & 346 & 42.1 & 269 & 32.8 & 822 \\
\hline Other fruits and vegetables & 142 & 28.1 & 204 & 40.3 & 160 & 31.6 & 506 \\
\hline Total & 1514 & & 2239 & & 1774 & & 5057 \\
\hline
\end{tabular}

Table 3 Minimum dietary diversity among children aged between 6 and 23 months, Ethiopia, 2016

\begin{tabular}{llll}
\hline Minimum dietary diversity & Sample size & $\boldsymbol{n}$ & $\%$ \\
\hline $\begin{array}{c}\text { Minimum dietary diversity, breastfeed } \\
(6-11 \text { months })\end{array}$ & 981 & 102 & 9.6 \\
$\begin{array}{c}\text { Minimum dietary diversity, non-breastfeed } \\
(6-11 \text { months })\end{array}$ & 63 & 18 & 3.5 \\
$\begin{array}{c}\text { Minimum dietary diversity, breastfeed } \\
(12-17 \text { months })\end{array}$ & 999 & 179 & 5.8 \\
$\begin{array}{c}\text { Minimum dietary diversity, non-breastfeed } \\
(12-17 \text { months })\end{array}$ & 93 & 19 & 4.9 \\
$\begin{array}{c}\text { Minimum dietary diversity, breastfeed } \\
(18-23 \text { months })\end{array}$ & 638 & 88 & 7.25 \\
$\begin{array}{c}\text { Minimum dietary diversity, non-breastfeed } \\
(18-23 \text { months })\end{array}$ & 198 & 36 & 5.5 \\
\hline
\end{tabular}

\begin{tabular}{r|rr} 
Variable & VIF & I/VIF \\
\hline reading_fr $\sim$ y & & \\
1 & 1.28 & 0.779701 \\
listning_f $\sim$ y & 1.14 & 0.877813 \\
1 & & \\
2 & 1.29 & 0.777955 \\
father_edu n & 1.36 & 0.737564 \\
1 & 1.69 & 0.590851 \\
2 & 1.87 & 0.533791 \\
wealth_index & & \\
2 & 1.19 & 0.839580 \\
3 & 1.25 & 0.801498 \\
4 & 1.28 & 0.781264 \\
5 & 2.14 & 0.467723 \\
\hline Mean VIF & 1.45 &
\end{tabular}

Fig. 1 Multicollinearity test for predictors in the final model significantly associated with inadequate minimum dietary diversity of children 6-23 months, EDHS 2016 with improving minimum dietary diversity of children $[18,19]$.

Being richest in household wealth index has been shown negatively associated with inadequate minimum dietary diversity of a child. Similarly, household wealth was found as predictor of minimum dietary diversity in the four South Asian countries where variable is available, indicating the important role of household resources in determining complementary feeding of children [9]. In our study, especially children who were living in a richest household had significantly less chance to be inadequate in meeting the recommended minimum dietary diversity. This was in line with other study conducted in Ethiopia using the 2011 DHS [20].

Moreover, in the present study education level of fathers has been assessed and became statistically associated with meeting the recommended diversity of food. Compared to no education, as the education level of the fathers increased, the children were more likely to get the recommended minimum dietary diversity. The same finding was also found in Nepalese study [21]. This shows that educated fathers can understand the education message that they got from different mass media like radio or newspaper which more likely enable them to be engaged in achieving their children to the minimum dietary diversity. Since EDHS is using cross-sectional study design, the limitations of this study were causal inferences between associated factors and inadequate MDD cannot be made.

\section{Conclusion}

The study revealed different predictors that were significantly associated with the selected WHO recommended complementary feeding practice indicator (minimum 
Table 4 Bivariate and multivariate logistic regression between different level predictors and inadequate minimum dietary diversity of children aged 6-23 months, EDHS 2016

\begin{tabular}{|c|c|c|c|c|c|c|c|}
\hline \multirow[t]{2}{*}{ Characteristics } & \multirow[t]{2}{*}{ COR } & \multicolumn{6}{|c|}{ Risk for inadequate minimum dietary diversity } \\
\hline & & $95 \%(\mathrm{Cl})$ & $p$ value & AOR & $95 \%(\mathrm{Cl})$ & $p$ value & \\
\hline Reads newspaper or magazine & & & & & & & $<0.001$ \\
\hline \multicolumn{8}{|l|}{ Not at all $[R]$} \\
\hline Less than once a week & 0.22 & $(0.13,0.38)$ & 0.000 & 0.44 & $(0.23,0.83)$ & 0.012 & \\
\hline At least once a week & 0.07 & $(0.03,0.19)$ & 0.000 & 0.19 & $(0.07,0.46)$ & 0.000 & \\
\hline Listen to radio & & & & & & & $<0.001$ \\
\hline \multicolumn{8}{|l|}{ Not at all $[R]$} \\
\hline Less than once a week & 0.47 & $(0.29,0.74)$ & 0.001 & 0.72 & $(0.42,1.24)$ & 0.245 & \\
\hline At least once a week & 0.23 & $(0.16,0.33)$ & 0.000 & 0.43 & $(0.30,0.62)$ & 0.000 & \\
\hline Father's education & & & & & & & $<0.001$ \\
\hline \multicolumn{8}{|l|}{ No education $[R]$} \\
\hline Primary & 0.46 & $(0.28,0.75)$ & 0.002 & 0.59 & $(0.37,0.94)$ & 0.028 & \\
\hline Secondary and higher & 0.25 & $(0.15,0.40)$ & 0.002 & 0.62 & $(0.36,1.09)$ & 0.102 & \\
\hline Household wealth index & & & & & & & $<0.001$ \\
\hline \multicolumn{8}{|l|}{ Poorest $[R]$} \\
\hline Poorer & 0.58 & $(0.31,1.06)$ & 0.081 & 0.66 & $(0.37,1.17)$ & 0.156 & \\
\hline Middle & 0.56 & $(0.31,1.02)$ & 0.059 & 0.79 & $(0.44,1.41)$ & 0.433 & \\
\hline Richer & 0.41 & $(0.22,0.75)$ & 0.004 & 0.69 & $(0.38,1.27)$ & 0.240 & \\
\hline Richest & 0.16 & $(0.08,0.29)$ & 0.000 & 0.40 & $(0.21,0.76)$ & 0.005 & \\
\hline
\end{tabular}

dietary diversity). After lots of variables have been assessed significantly, associated factors were: reading frequency of newsletter or magazine, listening frequency to radio, father's educational level and household wealth index. Minimum dietary diversity is still low in Ethiopia, and the most common food groups consumed were dairy products and grain, roots and tubers. This shows the gap that mothers feed their child the most and easy accessible food rather than of diverse food. This study also came up with the result that increment in the household wealth had a good impact to feed the child to the diverse food groups for better growth and development. By increasing the accessibility, awareness creation using radio, newspaper or magazine was one of the significant game changer methods to improve the inappropriate complementary feeding practice.

Since increasing dietary diversity at the national level is an effective measure to childhood malnutrition reduction and improving the nutritional status of children [8,22], this study suggests the possible targets of future interventions to improve minimum dietary diversity in Ethiopia. National governments should build the capacity of small-scale producers, particularly women, by ensuring access to public services such as infrastructure, financial services, information and training of appropriate feeding practice. National governments must provide access to education and strengthen social safety nets to ensure that all members of society have income security and can access essential foods and health care. International or local donors should play their pivotal role by funding efforts to achieve the SDGs.

\section{Abbreviations}

AOR: adjusted odds ratio; Cl: confidence interval; COR: crude odds ratio; DHS: demographic health survey; EAs: enumeration areas; EDHS: Ethiopia demographic health survey; MDD: minimum dietary diversity; PSNP: Productive Safety Net Program; SDGs: Sustainable Development Goals; SVY: survey; WHO: World Health Organization; VIF: variance inflation factor.

\section{Authors' contributions}

TE conceived the study, designed, wrote the paper, conducted data analysis, drafted and finalized the manuscript for publication. GK, YB, AM and TM assisted with critical reviewing papers. All authors read and approved the final manuscript.

\section{Author details}

${ }^{1}$ Department of Public Health, College of Medicine and Health Sciences (CMHS), Debre Markos University (DMU), Debre Markos, Ethiopia. ${ }^{2}$ Department of Midwifery, College of Medicine and Health Sciences (CMHS), Debre Markos University (DMU), Debre Markos, Ethiopia. ${ }^{3}$ Department of Midwifery, College of Medicine and Health Sciences (CMHS), Debre Birhan University (DMU), Debre Birhan, Ethiopia. 


\section{Acknowledgements}

We would like to thank the DHS program who let us to access the EDHS data set.

\section{Competing interests}

The authors declare that they have no competing interests.

\section{Availability of data and materials}

Supporting data for the current study are available from the corresponding author on reasonable request. The EDHS data set was retrieved from https:// dhsprogram.com/data/available-datasets.cfm.

\section{Consent for publication}

Not applicable.

\section{Ethics approval and consent to participate}

Secondary analysis of the data is conducted through ethical way of accessing to DHS data. First and foremost, online request to access the data set was sent to the CSA or ORC Macro (Demographic and Health Survey) and we have been authorized to download data from the Demographic and Health Surveys (DHS) online archive.

\section{Funding}

All the authors dedicated their additional working hours to develop this paper with no specific grant from any funding agency.

\section{Publisher's Note}

Springer Nature remains neutral with regard to jurisdictional claims in published maps and institutional affiliations.

Received: 31 July 2018 Accepted: 12 September 2018

Published online: 19 September 2018

\section{References}

1. World Health Organization. Report of the expert consultation of the optimal duration of exclusive breastfeeding, Geneva, Switzerland, 28-30 March 2001. 2001.

2. World Health Organization. Complementary feeding: report of the global consultation, and summary of guiding principles for complementary feeding of the breastfed child. 2003.

3. UNICEF, WHO, World Bank Group. Levels and trends in child malnutrition. 2018.

4. Organization WH. World health statistics 2018: monitoring health for the SDGs, sustainable development goals. 2018

5. World Health Organization. Indicators for assessing infant and young child feeding practices: part 1: definitions: conclusions of a consensus meeting held 6-8 November 2007 in Washington. 2008.
6. Torheim L, Ouattara F, Diarra M, Thiam F, Barikmo I, Hatløy A, et al. Nutrient adequacy and dietary diversity in rural Mali: association and determinants. Eur J Clin Nutr. 2004:58(4):594.

7. Ahmad I, Khalique N, Khalil S. Dietary diversity and stunting among infants and young children: a cross-sectional study in Aligarh. Indian J Community Med. 2018;43(1):34.

8. Borkotoky K, Unisa S, Gupta AK. State-level dietary diversity as a contextual determinant of nutritional status of children in India: a multilevel approach. J Biosoc Sci. 2018:50(1):26-52.

9. Menon P. The crisis of poor complementary feeding in South Asia: where next? Matern Child Nutr. 2012;8:1-4

10. Devereux S, Sabates-Wheeler R, Slater R, Tefera M, Brown T, Teshome A. Ethiopia's Productive Safety Net Programme (PSNP): 2008 Assessment Report. IDS, Sussex. 2008

11. World Food Programme. Global Report on Food Crises. March, 2017.

12. Gleixner S, Keenlyside N, Viste E, Korecha D. The El Niño effect on Ethiopian summer rainfall. Clim Dyn. 2017:49(5-6):1865-83.

13. World Health Organization, UNICEF. Core Questions on Drinking Water and Sanitation For Household Surveys. 2006.

14. Central Statistical Agency (CSA) [Ethiopia] and ICF. Ethiopia Demographic and Health Survey 2016. Addis Ababa, Ethiopia, and Rockville, Maryland, USA: CSA and ICF; 2016

15. Hosmer DW Jr, Lemeshow S, Sturdivant RX. Applied logistic regression. New York: Wiley; 2013.

16. Joshi N, Agho KE, Dibley MJ, Senarath U, Tiwari K. Determinants of inappropriate complementary feeding practices in young children in Nepal: secondary data analysis of Demographic and Health Survey 2006. Matern Child Nutr. 2012;8:45-59.

17. Patel A, Pusdekar Y, Badhoniya N, Borkar J, Agho KE, Dibley MJ. Determinants of inappropriate complementary feeding practices in young children in India: secondary analysis of National Family Health Survey 2005-2006. Matern Child Nutr. 2012;8:28-44.

18. Beyene M, Worku AG, Wassie MM. Dietary diversity, meal frequency and associated factors among infant and young children in Northwest Ethiopia: a cross-sectional study. BMC Public Health. 2015;15(1):1007.

19. Blackstone S, Sanghvi T. A comparison of minimum dietary diversity in Bangladesh in 2011 and 2014. Matern Child Nutr. 2018. https://doi. org/10.1111/men.12609

20. Aemro M, Mesele M, Birhanu Z, Atenafu A. Dietary diversity and meal frequency practices among infant and young children aged 6-23 months in Ethiopia: a secondary analysis of Ethiopian demographic and health survey 2011. J Nutr Metab. 2013:2013(1):1.

21. Khanal V, Sauer K, Zhao Y. Determinants of complementary feeding practices among Nepalese children aged 6-23 months: findings from demographic and health survey 2011. BMC Pediatr. 2013;13(1):131.

22. Arimond M, Ruel MT. Dietary diversity is associated with child nutritional status: evidence from 11 demographic and health surveys. J Nutr. 2004;134(10):2579-85.

Ready to submit your research? Choose BMC and benefit from

- fast, convenient online submission

- thorough peer review by experienced researchers in your field

- rapid publication on acceptance

- support for research data, including large and complex data types

- gold Open Access which fosters wider collaboration and increased citations

- maximum visibility for your research: over 100M website views per year

At $B M C$, research is always in progress.

Learn more biomedcentral.com/submissions 